\title{
Purinergic signaling elements are correlated with coagulation players in peripheral blood and leukocyte samples from COVID-19 patients
}

\author{
lago C. Schultz ${ }^{1}$ - Ana Paula S. Bertoni ${ }^{1} \cdot$ Márcia R. Wink $^{1}$ (D
}

Received: 21 June 2021 / Revised: 6 December 2021 / Accepted: 10 December 2021 / Published online: 29 January 2022

(c) The Author(s), under exclusive licence to Springer-Verlag GmbH Germany, part of Springer Nature 2021

\begin{abstract}
For over a year, the coronavirus disease 2019 has been affecting the world population by causing severe tissue injuries and death in infected people. Adenosine triphosphate (ATP) and the nicotinamide adenine dinucleotide (NAD +) are two molecules that are released into the extracellular microenvironment after direct virus infection or cell death caused by hyper inflammation and coagulopathy. Also, these molecules are well known to participate in multiple pathways and have a pivotal role in the purinergic signaling pathway. Thus, using public datasets available on the Gene Expression Omnibus (GEO), we analyzed raw proteomics data acquired using mass spectrometry (the gold standard method) and raw genomics data from COVID-19 patient samples obtained by microarray. The data was analyzed using bioinformatics and statistical methods according to our objectives. Here, we compared the purinergic profile of the total leukocyte population and evaluated the levels of these soluble biomolecules in the blood, and their correlation with coagulation components in COVID-19 patients, in comparison to healthy people or non-COVID-19 patients. The blood metabolite analysis showed a stage-dependent inosine increase in COVID-19 patients, while the nucleotides ATP and ADP had positive correlations with fibrinogen and other coagulation proteins. Also, ATP, ADP, inosine, and hypoxanthine had positive and negative correlations with clinical features. Regarding leukocyte gene expression, COVID-19 patients showed an upregulation of the $P 2 R X 1, P 2 R X 4, P 2 R X 5, P 2 R X 7$, $P 2 R Y 1, P 2 R Y 12, P A N X 1, A D O R A 2 B, N L P R 3$, and $F 3$ genes. Yet, the ectoenzymes of the canonical and non-canonical adenosinergic pathway (ENTPDI and $C D 38$ ) are upregulated, suggesting that adenosine is produced by both active adenosinergic pathways. Hence, approaches targeting these biomolecules or their specific purinoreceptors and ectoenzymes may attenuate the high inflammatory state and the coagulopathy seen in COVID-19 patients.
\end{abstract}

\section{Key messages}

- Adenosinergic pathways are modulated on leukocytes from COVID-19 patients.

- Plasmatic inosine levels are increased in COVID-19 patients.

- ATP, ADP, AMP, hypoxanthine, and inosine are correlated with coagulation players.

- The nucleotides and nucleosides are correlated with patients' clinical features.

- The P2 receptors and ectoenzymes are correlated with Tissue factor in COVID-19.

Keywords COVID-19 $\cdot$ SARS-CoV-2 $\cdot$ Leukocyte $\cdot$ Purinergic signaling $\cdot$ Inosine

\section{Introduction}

Ana Paula S. Bertoni and Márcia R. Wink are senior authors.

Márcia R. Wink

mwink@ufcspa.edu.br; marciawink@yahoo.com.br

1 Departamento de Ciências Básicas da Saúde, Laboratório de Biologia Celular, Universidade Federal de Ciências da Saúde de Porto Alegre (UFCSPA), Rua Sarmento Leite, 245 Sala 304, Porto Alegre, RS 90050-170, Brazil
Since the end of 2019, the world has been affected by the global pandemic of coronavirus disease 2019 (COVID-19), caused by a new $\beta$-virus called severe acute respiratory syndrome coronavirus 2 (SARS-CoV-2) [1]. So far, more than 228 million people have been infected and 4.6 million have died worldwide (covid19.who.int). This singlestranded RNA virus has a similarity of $79 \%$ with the previous SARS-CoV [2], and variants of the new coronavirus 
have already appeared worldwide [3-5]. This virus uses the angiotensin-converting enzyme 2 (ACE2) receptor to enter a wide range of cell types, including alveolar, endothelial, kidney, heart, and brain cells [6-10], with the assistance of the transmembrane protease serine 2 (TMPRSS2) and possibly other proteases [11].

Around $20 \%$ of infected people are symptomatic, and the most common manifestations are fever, cough, loss of taste and smell, and fatigue. According to the symptoms, the patients are stratified as having asymptomatic, mild, moderate, or severe COVID-19 [12, 13]. Within days after the viral infection, the severely ill patients develop pneumonia that usually progresses to acute respiratory distress syndrome (ARDS), requiring admission to the intensive unit care (ICU) and supplementation with exogenous oxygen [14]. The ICU patients have alterations in blood biomarkers associated with the severity and progression of the disease, such as elevated levels of circulating D-dimer $(>1 \mu \mathrm{g} / \mathrm{mL})$ [15-17], prolonged prothrombin time [18], elevated levels of pro-inflammatory cytokines, and chemokines $[15,19]$, especially IL-6, IL-1 $\beta$ and TNF- $\alpha$ [15, 20-23], C-reactive protein (CRP), lactate dehydrogenase (LDH), and the activation of the NLRP3 inflammasome [24].

Immunothrombosis is a defensive effector of the innate immune system. However, if uncontrolled, pathological thrombosis can emerge, mainly inside the microvessels [25]. Thrombotic complications are a major cause of morbimortality in COVID-19 patients, although the mechanism remains under investigation [26]. Around 45\% of ICU patients present with venous thromboembolic events (VTE) [27]. Post-mortem analysis of COVID-19 patients has revealed the presence of microthrombus in the lung vasculature [6], including in children [28]. Thus, the International Society on Thrombosis and Hemostasis (ISTH) recommended the administration of low molecular weight heparin to COVID19 patients to attenuate the lethality caused by these coagulopathies [29, 30].

Several research groups, including ours, have been repurposing approved medications [31] or indicating novel molecules and approaches to treat this new disease [10, 32-37]. Several vaccination protocols against COVID-19 are ongoing worldwide, but a satisfactory vaccination rate has not been achieved yet.

Due to viral infection, systemic inflammation, and coagulation disturbance, tissues are constantly damaged, releasing pathogen-associated molecular patterns (PAMPs) and damage-associated molecular patterns (DAMPs), including the extracellular molecule adenosine triphosphate (ATP) [19, 38, 39]. Extracellular ATP acts through paracrine and autocrine signaling pathways, acting as a strong "find me" signal for immune cell recruitment to damaged sites [40]. In physiological conditions, the release of ATP occurs by membrane pore formation or through pannexin channels and connexin hemichannels [41-43]. In the extracellular space, ATP acts as a signaling molecule through the $\mathrm{P} 2$ receptor (P2R) family, the subfamily of G protein-coupled metabotropic P2Y (P2Y $\left.\mathrm{Y}_{1,2,4,6,11-14}\right)$, and the ligand-gated ionotropic $\mathrm{P} 2 \mathrm{X}\left(\mathrm{P} 2 \mathrm{X}_{1-7}\right)$ [44]. In addition to receptor activation, ATP is hydrolyzed to adenosine diphosphate and monophosphate (ADP and AMP) by the ectonucleoside triphosphate diphosphohydrolase 1 (CD39/ENTPD1), and the ecto-5'nucleotidase (CD73/NT5E) converts the AMP to adenosine. Inosine is then formed through adenosine deaminase (ADA) (Fig. 1), completing the canonical adenosinergic pathway. However, there is also a non-canonical adenosinergic pathway that uses the extracellular nicotinamide adenine dinucleotide $\left(\mathrm{NAD}^{+}\right)$molecule. This alternative pathway follows the axis of the CD38/CD203a(ENPP1)/CD73/ADA ectoenzymes, which catabolize the $\mathrm{NAD}^{+}$into ADP-ribose (ADPR), AMP, adenosine, and inosine, sequentially (Fig. 1) [45].

Adenosine is known as an anti-inflammatory and healing molecule of the purinergic system [46]. It activates the adenosine receptors ( $\mathrm{P} 1$ receptors) $\mathrm{A}_{1}, \mathrm{~A}_{2 \mathrm{~A}}, \mathrm{~A}_{2 \mathrm{~B}}$, and $\mathrm{A}_{3}$, encoded by the ADORA1, ADORA2, ADORA2A, ADORA2B, and $A D O R A 3$ genes, respectively. In COVID-19, researchers suggest that targeting the adenosine receptors, specifically $\mathrm{A}_{2 \mathrm{~A}}$, may be an alternative to attenuate lung inflammation and thrombotic consequences of the disease [47]. Also, adenosine is metabolized by ADA, resulting in inosine, hypoxanthine, xanthine, and uric acid. Regarding these sequential metabolites, bronchoalveolar lavage fluid (BALF) and blood samples of COVID-19 patients showed alterations in the metabolization of adenosine to inosine [48] and inosine to hypoxanthine [49], indicating the relevant role of purines in the pathophysiology of COVID-19.

Therefore, the main objective of this study was to analyze whether alterations in the purinergic system profile of leukocytes and soluble blood metabolites exist, as well as their relationship with key points of coagulopathy and clinical features manifested by COVID-19 patients. In order to do this, available public datasets were employed to analyze genomic and metabolomic data from peripheral blood samples from patients with and without COVID-19, to assess positive and negative correlations between the purinergic elements, coagulation, and inflammatory players, in order to establish a purinergic profile of COVID-19 patients.

\section{Materials and methods}

To analyze the adenine nucleotides (ATP, ADP, AMP), adenosine, and its sequential metabolites (inosine, hypoxanthine, xanthine), two datasets were downloaded and used in the present study. The first dataset, entitled "Largescale Multi-omic Analysis of COVID-19 Severity," was 


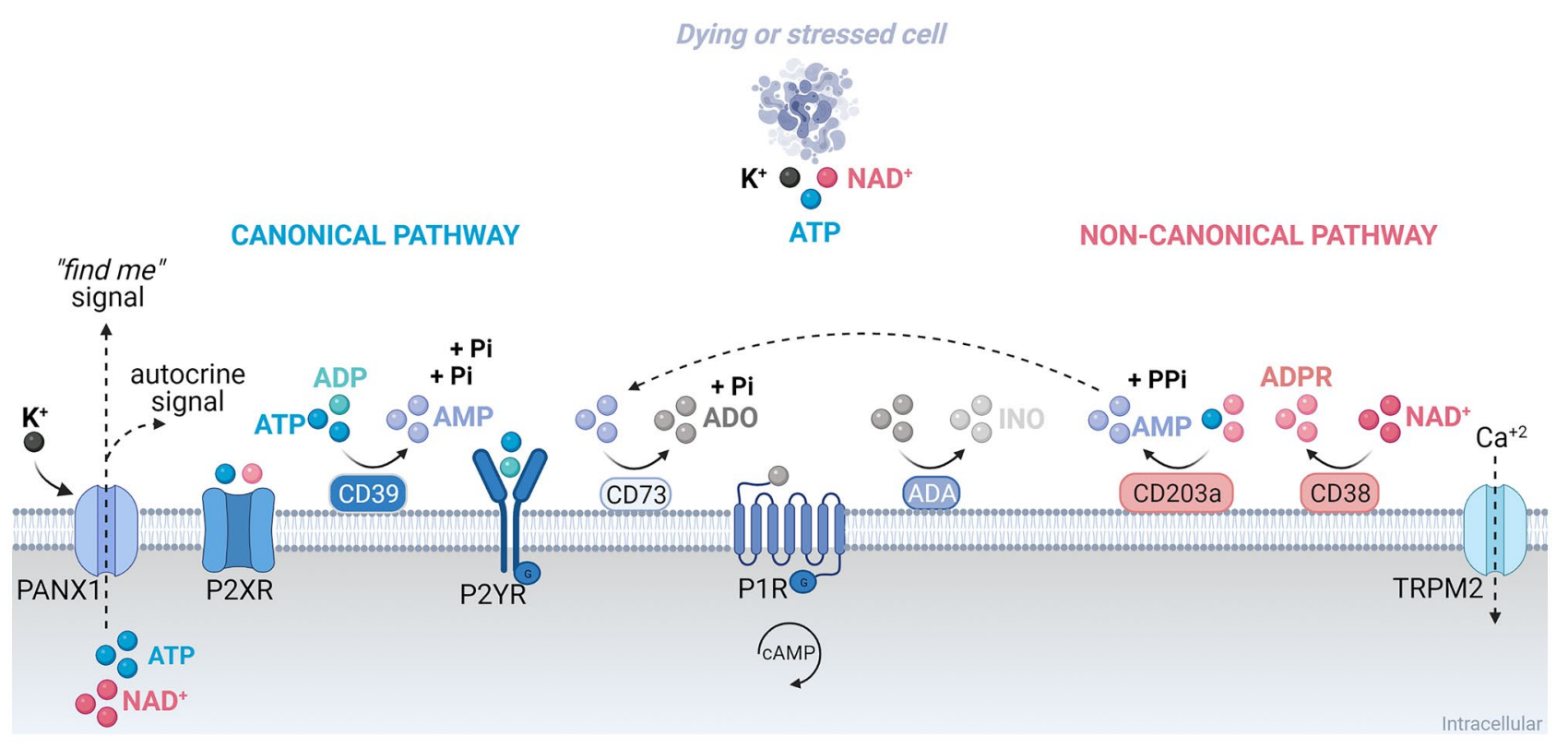

Fig. 1 Purinergic signaling comprises the canonical and non-canonical adenosinergic pathways. The canonical pathway is responsible for the production of the anti-inflammatory biomolecule adenosine (ADO) starting from the adenosine triphosphate (ATP) which is hydrolyzed to adenosine diphosphate (ADP) and adenosine monophosphate (AMP) by the ectoenzymes following the axis CD39/CD73. The non-canonical

generated by Katherine Overmyer et al. in 2020 and is composed of blood samples from 102 COVID-19 and 26 nonCOVID-19 patients from Albany Medical Center in Albany, NY, USA [50]. The raw data on nucleotide and nucleoside levels are available and were obtained via GitHub (https:// github.com/ijmiller2/COVID-19_Multi-Omics/), and the quantitative measurements of plasma metabolites were analyzed by liquid chromatography coupled to mass spectrometry (LC-MS). From this study, data on ATP, ADP, AMP, and hypoxanthine levels were used, and clinical features were also used to correlate with these biomolecules. The second dataset was provided by Shen et al. [51], and the data on AMP, adenosine, hypoxanthine, inosine, and xanthine levels from 25 healthy, 25 non-COVID-19, 21 severe COVID-19, and 25 non-severe COVID-19 patients are available in Supplemental Information Table S2 of the study entitled "Proteomic and Metabolomic Characterization of COVID-19 Patient Sera" [51].

For Overmyer's study, we also downloaded the GSE157103 dataset from Gene Expression Omnibus (GEO) (https://www.ncbi.nlm.nih.gov/geo/query/acc.cgi?acc= GSE157103), which provided the transcriptomic data for total blood leukocytes from 101 COVID-19 and 149 nonCOVID-19 patients. Another two datasets available on the GEO, GSE154998 [52] and GSE160351 [53], were also downloaded to perform the analysis of leukocyte genomic profiles from patients with COVID-19. adenosinergic pathway has the same function of adenosine formation, although this alternative way uses the $\mathrm{NAD}^{+}$which is metabolized by the axis CD38/CD203a/CD73. After the adenosine is formed, it can activate the $\mathrm{P} 1$ receptors or be metabolized by the adenosine deaminase (ADA) and originate the inosine

To perform the statistical analysis, the Shapiro-Wilk test was applied to determine sample normality; multiple groups were compared using one-way ANOVA and the Tukey post hoc test. Mann-Whitney $U$ test, Student's $t$-test, and paired Student's $t$-test were used, as appropriate, implemented using SPSS software (Version 21). Correlations between the levels of biomolecules and clinical features or protein levels were assessed using Pearson's correlation. Graphs were created with GraphPad Prism (Version 7).

\section{Results}

\section{Identification of plasma nucleotide and nucleoside levels}

To analyze the profile of plasma nucleotides and nucleosides of COVID-19 patients, we used two studies measuring their levels using high-resolution mass spectrometry. This methodology, due to its accurate measurements and high sensitivity, has emerged as an efficient alternative to identify and quantify plasma metabolites even at low concentrations.

Figure 2A shows the levels of ATP, ADP, AMP, and hypoxanthine in both groups, non-COVID-19 and COVID19, stratified by Overmyer et al. In Fig. 2B, the analysis of these biomolecules shows no statistical significance between the two groups. However, among the biomolecules, the analyses showed a higher correlation between ATP and ADP 

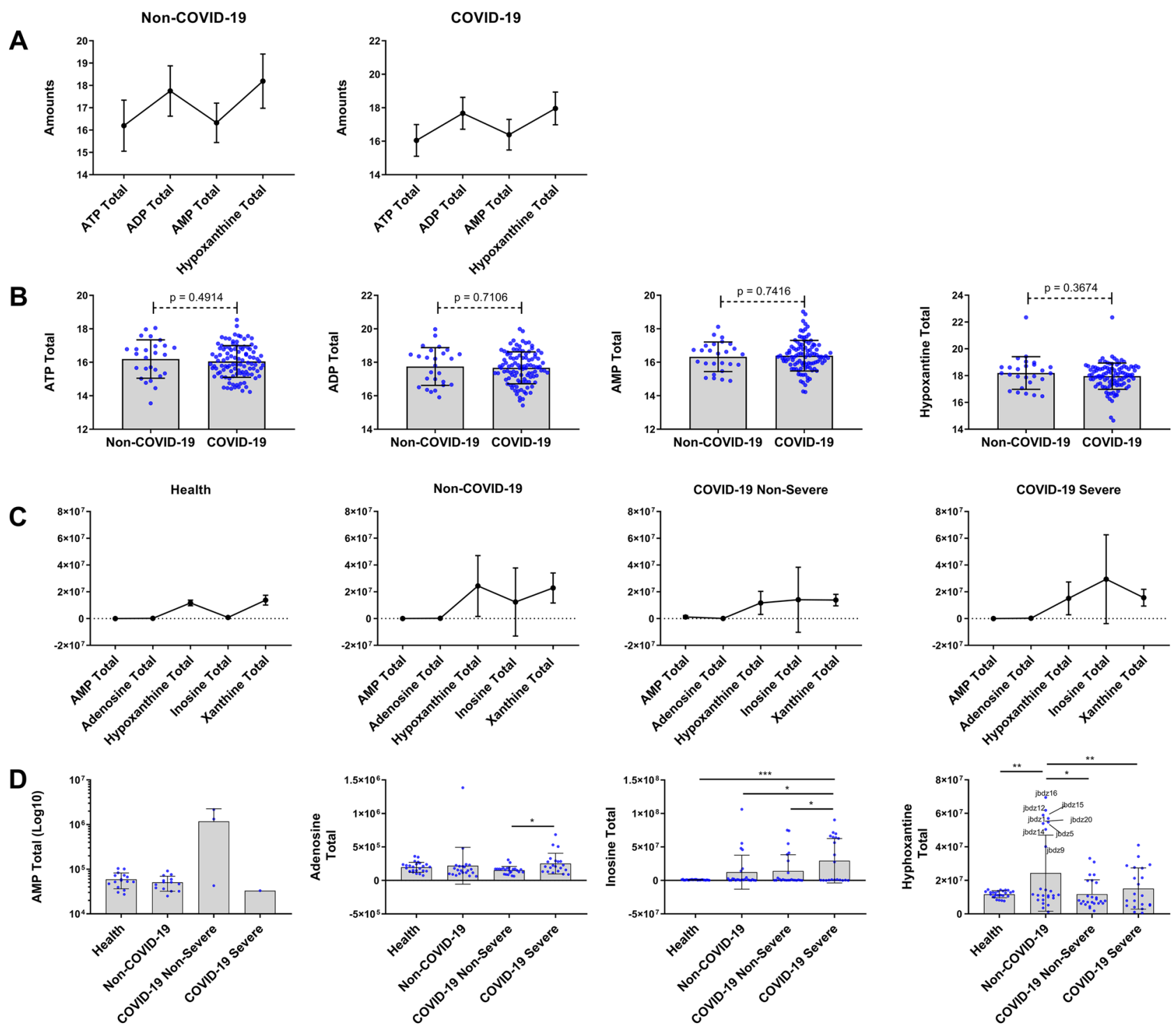

Fig. 2 Nucleotides and nucleosides levels and their comparison among the analyzed groups in each study performed by Overmyer et al. [50] (A and $\mathbf{B}$ ) and Shen et al. [51] (C and D)

$(r=0.931 ; n=103 ; p<0.0001)$, and with AMP $(r=0.735$; $n=103 ; p<0.0001)$, but not with hypoxanthine $(r=-0.003$; $n=103 ; p=0.972$ ).

Using the data available from the study performed by Shen et al., Fig. 2C shows the measurements of AMP, adenosine, hypoxanthine, inosine, and xanthine from four groups, healthy, non-COVID-19, non-severe COVID-19, and severe COVID-19, stratified by the authors of the study. There is no significant difference between the biomolecule levels in each group. On the other hand, when compared between the four groups, as shown in Fig. 2D, the inosine levels were significantly increased in the severe COVID-19 group, when compared to the healthy, non-COVID-19, and non-severe COVID-19 groups (respectively, $p<0.0001, p=0.0169$; and $p=0.0327$ ).
For hypoxanthine, it was possible to note that the nonCOVID-19 group comprises two distinct clusters. One is composed of eight samples $(8 / 25 ; 32 \%)$, which were responsible for the significant increase in the amounts of hypoxanthine when compared with the healthy group $(p=0.0016)$, non-severe COVID-19 $(p=0.0015)$, and severe COVID-19 ( $p=0.0253)$ groups. The other cluster was composed of 17 samples $(17 / 25 ; 68 \%)$ and shows no significant difference from the other groups.

\section{Correlations of clinical features with purine nucleotide and nucleoside levels}

Considering that purine biomolecules are associated with blood coagulation, platelet activation, and leukocytes 
chemotaxis, we analyzed whether they could be associated with the different stages or clinical features of COVID-19 patients.

In Table 1, we show the correlations between purine biomolecules and clinical features presented by the patients of each group. Using the data from Shen et al., inosine showed negative correlations with white blood cells (WBC), monocyte count, and platelet count in the non-severe COVID-19 group. In the severe COVID-19 group, the levels of inosine showed a negative correlation with monocyte count. Adenosine showed a positive correlation with platelet count in the non-COVID-19 group, while hypoxanthine showed a negative correlation in the non-severe COVID-19 group.

Aiming to analyze the relationship between the purines and coagulation system components, and two severity and mortality scores, we used the metabolomics data from a study by Overmyer et al. This data regarding the amounts of ATP, ADP, and AMP was compared with the information on fibrinogen, Acute Physiology and Chronic Health Evaluation II (APACHE II) and Sequential Organ Failure Assessment (SOFA), C-reactive protein, and D-dimer from both groups (Table 1). Positive correlations between ATP $\times$ fibrinogen and ADP $\times$ fibrinogen are presented by both groups. The correlation of $\mathrm{AMP} \times$ fibrinogen is presented only by the non-COVID-19 group. ATP and ADP presented a negative correlation with SOFA in the non-COVID-19 group. Also, in the non-COVID-19 group, ATP and ADP presented a negative correlation with APACHE II. Hypoxanthine showed a positive correlation with APACHE II in both groups. The samples of the COVID-19 group showed positive correlations between ATP and AMP and C-reactive protein, and the hypoxanthine levels showed a positive correlation with D-dimer levels. It is important to note that Overmyer et al., unlike Shen et al., stratified the patients in their study into only two groups and both are comprised of patients admitted to the hospital with COVID-19 symptoms. The difference between them is that the COVID-19 groups are those patients with molecular diagnosis real-time quantitative polymerase chain reaction (RT-qPCR) positive for SARSCoV-2 infection.

There were positive correlations between inosine and coagulation metabolites such as fibrinopeptide A516 $(n=19$; $p=0.0291 ; r=0.5005)$ and two other peptides derived from fibrinopeptide A, ADSGEGDFXAEGGGVR $(n=14$; $p=0.0272 ; r=0.5873)$ and DSGEGDFXAEGGGVR $(n=22 ; p=0.0158 ; r=0.5081)$, in the non-severe COVID19 group.

Table 1 Correlation of purine biomolecules with clinical features presented by the patients of each group in their respective study

\begin{tabular}{|c|c|c|c|c|c|}
\hline Overmyer data & & ATP & ADP & AMP & Hypoxanthine \\
\hline \multirow[t]{2}{*}{ Fibrinogen } & Non-COVID-19 & $0.618 *(n=14)$ & $0.632 * * *(n=14)$ & & \\
\hline & COVID-19 & $0.358 * *(n=81)$ & $0.410 * * *(n=81)$ & $0.328 *(n=81)$ & \\
\hline \multirow[t]{2}{*}{ SOFA } & Non-COVID-19 & $-0.593 *(n=17)$ & $-0.495^{*}(n=17)$ & & \\
\hline & COVID-19 & & & & \\
\hline \multirow[t]{2}{*}{ APACHE II } & Non-COVID-19 & $-0.643^{*}(n=17)$ & $-0.601 *(n=17)$ & & $0.598 *(n=17)$ \\
\hline & COVID-19 & & & & $0.277 *(n=58)$ \\
\hline \multirow[t]{2}{*}{ CRP } & Non-COVID-19 & & & & \\
\hline & COVID-19 & $0.206^{*}(n=94)$ & & $0.251 *(n=94)$ & \\
\hline \multirow[t]{2}{*}{ D-dimer } & Non-COVID-19 & & & & \\
\hline & COVID-19 & & & & $0.317 *(n=87)$ \\
\hline Shen data & & Adenosine & Inosine & Hypoxanthine & Xanthine \\
\hline \multirow[t]{3}{*}{ Platelet count $\left(\times 10^{9} / \mathrm{L}\right)$} & Non-COVID-19 & $0.443^{*}(n=22)$ & & & \\
\hline & COVID-19_Non-Severe & & $-0.5121 *(n=24)$ & & \\
\hline & COVID-19_Severe & & & & \\
\hline \multirow[t]{3}{*}{ WBC count $\left(\times 10^{9} / \mathrm{L}\right)$} & Non-COVID-19 & & & & \\
\hline & COVID-19_Non-Severe & & $-0.409 *(n=25)$ & & \\
\hline & COVID-19_Severe & & & & \\
\hline \multirow[t]{3}{*}{ Monocyte count $\left(\times 10^{9} / \mathrm{L}\right)$} & Non-COVID-19 & & & & \\
\hline & COVID-19_Non-Severe & & $-0.459^{*}(n=25)$ & $-0.466 *(n=25)$ & \\
\hline & COVID-19_Severe & & & & \\
\hline \multirow[t]{3}{*}{ Lymphocyte count $\left(\times 10^{9} / \mathrm{L}\right)$} & Non-COVID-19 & & & & \\
\hline & COVID-19_Non-Severe & & & & \\
\hline & COVID-19_Severe & & & & \\
\hline
\end{tabular}

$* p<0.05 ; * * p<0.01 ; * * * p<0.001$ 
In addition, Overmyer et al. [50] present in their study a representative table with Kendall Tau correlation coefficients between total ATP and total ADP with peripheral blood metabolites. These correlations show that the nucleotides may be involved in blood coagulation and, therefore, we adapted and represented their results in Table S1 of the current study. Interestingly, we highlight that, among the molecules with a significant correlation with the nucleotides, there are molecules directly linked to the function of platelets, the major players in blood coagulation, such as ITGA2B, TUBB1, ITGB3, and PLEK.

\section{Correlations of circulating immune cells with purine nucleotide and nucleoside levels}

Another important question to investigate, regarding the modulation of plasma nucleotide and nucleoside levels, is the profile of the purine ectoenzymes and purinoreceptors on the peripheral blood immune cells.

Using transcriptomics data from the total leukocyte population, published by Overmyer et al. and available on GEO database (code GSE157103), we analyzed the expression of the purinergic system elements in the immune cells, as shown in Table 2, and their correlations with plasma levels of ATP, ADP, AMP, and hypoxanthine. In the study by Overmyer, there is no information about adenosine levels. As shown in Table S2, no correlation was observed between extracellular ATP, ADP, AMP, and hypoxanthine levels and the expression of ENTPD or ENPP ectoenzymes in leukocyte samples from COVID-19 patients. These results suggest that the catalysis of these biomolecules could be performed by other cells or by other ectoenzymes. Another point to consider is that it is possible that there is involvement and modulation of adenosine kinase $(A D K)$ activity and the equilibrative (SLC28A1, SLC28A2, and $S L C 28 A 3$ ) and even the concentrative (SLC29A1, SLC29A2, SLC29A3, and SLC29A4) adenosine transporters $[54,55]$. Indeed, adenosine could be produced by catalysis of the reversible hydrolysis of S-adenosylhomocysteine (SAH) by S-adenosylhomocysteine hydrolase (SAHH), which is encoded by the $A H C Y$ gene [56].

Considering the last hypothesis, in addition to the investigation of the CD39 (ENTPD1)/CD73 (NT5E)/ADA axis, we also looked at the expression of the ectonucleotidases that comprise the non-canonical adenosinergic pathway. This non-canonical pathway comprises the $C D 38 / C D 203 a$ (ENPP1)/CD73/ADA ectoenzymes, which catabolize the extracellular $\mathrm{NAD}^{+}$into ADPR by CD38, followed by ADPR hydrolysis to AMP by CD203a, with sequential production of adenosine by CD73.

The leukocyte blood samples from COVID-19 patients showed a significant upregulation of ENTPDI
$(55.64 \pm 2.69 ; n=100$ vs $37.79 \pm 4.592 ; n=26 ; p=0.0017)$, CD38 (7.021 $\pm 0.6108 ; n=100$ vs $1.458 \pm 0.1702$; $n=26 ; p<0.0001)$, and $A D A(15.3 \pm 1.135 ; n=100$ vs $10.54 \pm 1.422 ; n=26 ; p=0.0113)$ ectoenzymes, when compared with non-COVID-19 samples, therefore suggesting that both canonical and non-canonical pathways may be activated in these leukocytes. $A D A$ showed a relevant correlation with $C D 38$ ( $r=0.656 ; p<0.0001)$, but not with ENTPD1 $(r=-0.289 ; p=0.004)$. A strong correlation with $A D A$ was observed for ENTPD6 ( $r=0.897 ; p<0.0001)$ and with the concentrative nucleoside transporter SLC29A3 $(r=0.853$; $p<0.0001)$. Also, intermediate significant correlations ( $r>0.600)$ were revealed between $A D A$ and the DPP4, $A H C Y, G S D M B, E N T P D 5, P 2 R Y 6, P 2 R Y 8$ (the function of which is unknown in humans), P2RY10, P2RY11, ENPP5, $P 2 R X 4, N T 5 C, N T 5 C 3 B, S L C 29 A 1$, and $S L C 29 A 2$ genes. A further important correlation was observed between $C D 38$ and the pannexin channel PANXI $(r=0.730 ; p<0.0001)$, while ENTPD1 showed a weak correlation with PANX1 $(r=0.302 ; p=0.002)$.

Interestingly, no modulation of CD73 (NT5E) expression was observed. Also, the expression of CD203a (ENPP1) showed no modulation, while significant upregulations of ENPP4 (4.953 $\pm 0.3185 ; n=100$ vs $2.369 \pm 0.27 ; n=26$; $p<0.0001)$ and ENPP5 $(0.7706 \pm 0.08098 ; n=99$ vs $0.3904 \pm 0.0728 ; n=26 ; p=0.021$ ) were observed. However, it is important to highlight that, in these analyzed leukocyte samples, the expression of ENPPI was about 10, 4, 70, and 11 times lower than expression of ENPP2, ENPP3, ENPP4, and ENPP5, respectively.

Indeed, no difference was observed in $A D K$ or $A H C Y$ expression, but there were significant increases in the levels of $A H C Y$ isoforms AHCYL1 (22.95 $\pm 0.7359 ; n=100$ vs $18.28 \pm 0.9089 ; n=26 ; p=0.0026)$ and $A H C Y L 2$ $(3.154 \pm 0.1975 ; n=100$ vs $1.953 \pm 0.2109 ; n=26$; $p=0.0035$ ) in samples from COVID-19 patients.

Considering the high levels of inosine, we also investigated the expression of the purine nucleoside phosphorylase $(P N P)$ enzyme. As expected, the expression of this enzyme was higher in COVID-19 patients than in non-COVID-19 patients (respectively, $70.01 \pm 2.64 ; n=100$ vs $50.18 \pm 4.36$; $n=27 ; p=0.001)$.

The tissue factor expression (encoded by the $F 3$ gene) was also analyzed in leukocytes from the GSE157103 in the COVID-19 and non-COVID-19 groups, due to its essential role in blood coagulation. As shown in Fig. 3, higher expression $(p=0.0004)$ of this gene was observed in COVID-19 patients.

Analyzing the data available in the GSE154998 dataset, which is composed of COVID-19 $(n=7)$ and non-COVID-19 ICU patients $(n=7)$ [52], no significant difference was found for the purinergic enzymes or receptors (Table 2). 
Table 2 Relative expression of purinergic system components in total leukocytes with statistical differences between non-COVID-19 and COVID-19 patients

\begin{tabular}{|c|c|c|c|}
\hline \multirow[t]{3}{*}{ Gene } & $\begin{array}{l}\text { GSE157103 } \\
\text { PMID: } 33096026\end{array}$ & $\begin{array}{l}\text { GSE154998 } \\
\text { PMID: } 33306162\end{array}$ & $\begin{array}{l}\text { GSE160351 } \\
\text { PMID: 33208929 }\end{array}$ \\
\hline & $\begin{array}{l}\text { Sample: leukocytes } \\
\text { from whole blood }\end{array}$ & Sample: buffy coat cells & Sample: peripheral monocytes + CD14 \\
\hline & $\begin{array}{l}\text { Non_COVID } \\
(n=26) \text { vs COVID } \\
(n=100)\end{array}$ & $\begin{array}{l}\text { Non_COVID }(n=7) \text { vs } \\
\operatorname{COVID}(n=7)\end{array}$ & Health $(n=3)$ vs COVID $(n=6)$ \\
\hline ADORAI & $\varnothing$ & ND & $\varnothing$ \\
\hline ADORA2A & $\varnothing$ & $\varnothing$ & $\varnothing$ \\
\hline ADORA2B & $\uparrow$ & $\varnothing$ & $\uparrow$ \\
\hline ADORA3 & $\varnothing$ & $\varnothing$ & $\varnothing$ \\
\hline ENPP1 & $\varnothing$ & ND & $\varnothing$ \\
\hline ENPP2 & $\varnothing$ & $\varnothing$ & $\varnothing$ \\
\hline ENPP3 & $\varnothing$ & $\varnothing$ & $\varnothing$ \\
\hline ENPP4 & $\uparrow$ & $\varnothing$ & $\varnothing$ \\
\hline ENPP5 & $\uparrow$ & $\varnothing$ & $\varnothing$ \\
\hline ENPPG & $\varnothing$ & ND & $\varnothing$ \\
\hline ENPP7 & $\varnothing$ & ND & ND \\
\hline ENTPD1 & $\uparrow$ & $\varnothing$ & $\downarrow$ \\
\hline ENTPD2 & $\varnothing$ & ND & $\varnothing$ \\
\hline ENTPD3 & ND & ND & $\varnothing$ \\
\hline ENTPD4 & $\uparrow$ & $\varnothing$ & $\varnothing$ \\
\hline ENTPD5 & $\uparrow$ & $\varnothing$ & $\varnothing$ \\
\hline ENTPDG & $\varnothing$ & $\varnothing$ & $\varnothing$ \\
\hline ENTPD7 & $\varnothing$ & $\varnothing$ & $\varnothing$ \\
\hline ENTPD8 & $\varnothing$ & ND & $\varnothing$ \\
\hline$N T 5 E$ & $\varnothing$ & $\varnothing$ & $\varnothing$ \\
\hline$P 2 R X 1$ & $\uparrow$ & $\varnothing$ & $\varnothing$ \\
\hline$P 2 R X 2$ & ND & ND & $\varnothing$ \\
\hline$P 2 R X 3$ & ND & ND & $\varnothing$ \\
\hline$P 2 R X 4$ & $\varnothing$ & $\varnothing$ & $\uparrow$ \\
\hline$P 2 R X 5$ & $\uparrow$ & $\varnothing$ & $\downarrow$ \\
\hline$P 2 R X 6$ & ND & ND & $\varnothing$ \\
\hline$P 2 R X 7$ & $\uparrow$ & $\varnothing$ & $\varnothing$ \\
\hline P2RYI & $\uparrow$ & $\varnothing$ & $\uparrow$ \\
\hline P2RY2 & $\varnothing$ & ND & $\varnothing$ \\
\hline P2RY4 & ND & $\varnothing$ & $\varnothing$ \\
\hline P2RY5 & ND & ND & $\varnothing$ \\
\hline P2RYG & $\varnothing$ & $\varnothing$ & $\varnothing$ \\
\hline P2RY8 & $\varnothing$ & $\varnothing$ & $\varnothing$ \\
\hline P2RY10 & $\varnothing$ & $\varnothing$ & $\varnothing$ \\
\hline P2RY11 & ND & ND & $\varnothing$ \\
\hline P2RY12 & $\uparrow$ & $\varnothing$ & $\varnothing$ \\
\hline P2RY13 & $\varnothing$ & $\varnothing$ & $\downarrow$ \\
\hline P2RY14 & $\varnothing$ & $\varnothing$ & $\varnothing$ \\
\hline PANX1 & $\uparrow$ & $\varnothing$ & $\varnothing$ \\
\hline$A D A$ & $\uparrow$ & $\varnothing$ & $\varnothing$ \\
\hline DPP4 & $\uparrow$ & $\varnothing$ & $\varnothing$ \\
\hline CD38 & $\uparrow$ & $\varnothing$ & $\varnothing$ \\
\hline SLC28A1 & NA & NA & $\varnothing$ \\
\hline SLC28A2 & $\uparrow$ & NA & $\varnothing$ \\
\hline$S L C 28 A 3$ & $\uparrow$ & $\varnothing$ & $\downarrow$ \\
\hline
\end{tabular}


Table 2 (continued)

\begin{tabular}{|c|c|c|c|}
\hline \multirow[t]{3}{*}{ Gene } & $\begin{array}{l}\text { GSE157103 } \\
\text { PMID: 33096026 }\end{array}$ & $\begin{array}{l}\text { GSE154998 } \\
\text { PMID: } 33306162\end{array}$ & $\begin{array}{l}\text { GSE160351 } \\
\text { PMID: 33208929 }\end{array}$ \\
\hline & $\begin{array}{l}\text { Sample: leukocytes } \\
\text { from whole blood }\end{array}$ & Sample: buffy coat cells & Sample: peripheral monocytes $+\mathrm{CD14}$ \\
\hline & $\begin{array}{l}\text { Non_COVID } \\
(n=26) \text { vs COVID } \\
(n=100)\end{array}$ & $\begin{array}{l}\text { Non_COVID }(n=7) \text { vs } \\
\text { COVID }(n=7)\end{array}$ & Health $(n=3)$ vs COVID $(n=6)$ \\
\hline SLC29A1 & $\varnothing$ & $\varnothing$ & $\varnothing$ \\
\hline SLC29A2 & $\varnothing$ & NA & $\varnothing$ \\
\hline$S L C 29 A 3$ & $\varnothing$ & $\varnothing$ & $\varnothing$ \\
\hline SLC29A4 & $\uparrow$ & NA & $\varnothing$ \\
\hline$A D K$ & $\varnothing$ & $\varnothing$ & $\varnothing$ \\
\hline$A H C Y$ & $\varnothing$ & $\varnothing$ & $\uparrow$ \\
\hline AHCYLI & $\uparrow$ & $\varnothing$ & $\varnothing$ \\
\hline AHCYL2 & $\uparrow$ & $\varnothing$ & $\downarrow$ \\
\hline$N L R P 3$ & $\uparrow$ & $\varnothing$ & $\varnothing$ \\
\hline GSDMA & $\varnothing$ & NA & $\varnothing$ \\
\hline GSDMB & $\uparrow$ & $\varnothing$ & $\varnothing$ \\
\hline GSDMC & $\downarrow$ & $\varnothing$ & NA \\
\hline GSDMD & $\varnothing$ & $\varnothing$ & NA \\
\hline GSDME & $\varnothing$ & NA & NA \\
\hline TRPMI & NA & NA & $\varnothing$ \\
\hline TRPM2 & $\downarrow$ & $\varnothing$ & $\varnothing$ \\
\hline TRPM3 & NA & NA & $\varnothing$ \\
\hline TRPM4 & $\downarrow$ & $\varnothing$ & $\varnothing$ \\
\hline TRPM5 & NA & NA & $\varnothing$ \\
\hline TRPM6 & $\uparrow$ & $\varnothing$ & $\varnothing$ \\
\hline TRPM7 & $\uparrow$ & $\varnothing$ & $\varnothing$ \\
\hline TRPM8 & NA & NA & $\varnothing$ \\
\hline
\end{tabular}

$\uparrow$ gene upregulated, $\downarrow$ gene downregulated, $N A$ not available, $N D$ not detected, $\varnothing$ no gene expression variation

In the GSE160351 dataset, data obtained from monocyte samples of COVID-19 patients $(n=6)$ and healthy controls $(n=3)$ was analyzed regarding the purinergic profile, as shown in Table 2 . In this dataset, there was a higher expression of P2RX4 ( $p<0.001), P 2 R Y 1$ ( $p=0.0175), A D O R A 2 B$ $(p=0.043)$, and $A H C Y(p<0.001)$ in the COVID-19 group. On the other hand, there was reduction of expression of the P2RY13 ( $p=0.0157), P 2 R X 5(p=0.0389), E N T P D 1$ $(p<0.001), \operatorname{ENTPD} 4(p=0.0146), S L C 29 A 3(p=0.0204)$, and AHCYL2 $(p=0.0021)$ genes.

\section{Discussion}

In recent years, the use of bioinformatic approaches has increased and is now recognized as important tool in scientific research. According to the current literature, bioinformatic analysis of multi-omics data has the advantage of building networks in a faster and more integrative way, making protein-protein or protein-gene links, and providing more comprehensive insights about possible mechanistic pathways. Thus, combining data from multiple datasets is an alternative and reliable way to expand these connections, obtaining data from different layers and finding answers in a time- and money-saving way, which is necessary in the setting of the COVID-19 pandemic. It is important to highlight that the present paper is not based on prediction analysis. We performed our analysis entirely based on the raw proteomics data collected by mass spectrometry (the gold standard method) and raw genomics data obtained by microarray from COVID-19 patients' samples.

Multiple pathways show alterations in COVID-19 patients [57], including a prominent difference in purine metabolism, identified through targeted and untargeted metabolomics studies $[49,58]$. After infection with SARSCoV-2, cells expressing the ACE2 receptor are infected and COVID-19 develops, damaging the tissue and releasing a range of molecules throughout the body. These 


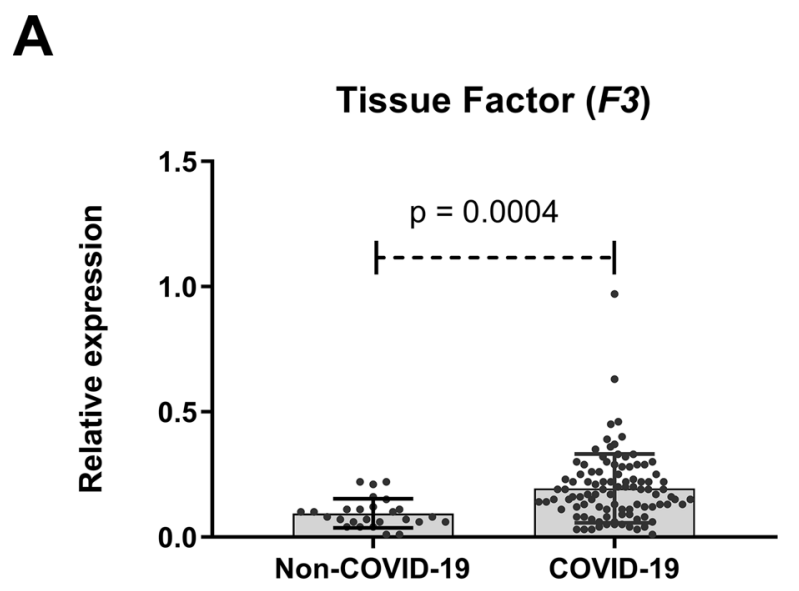

B

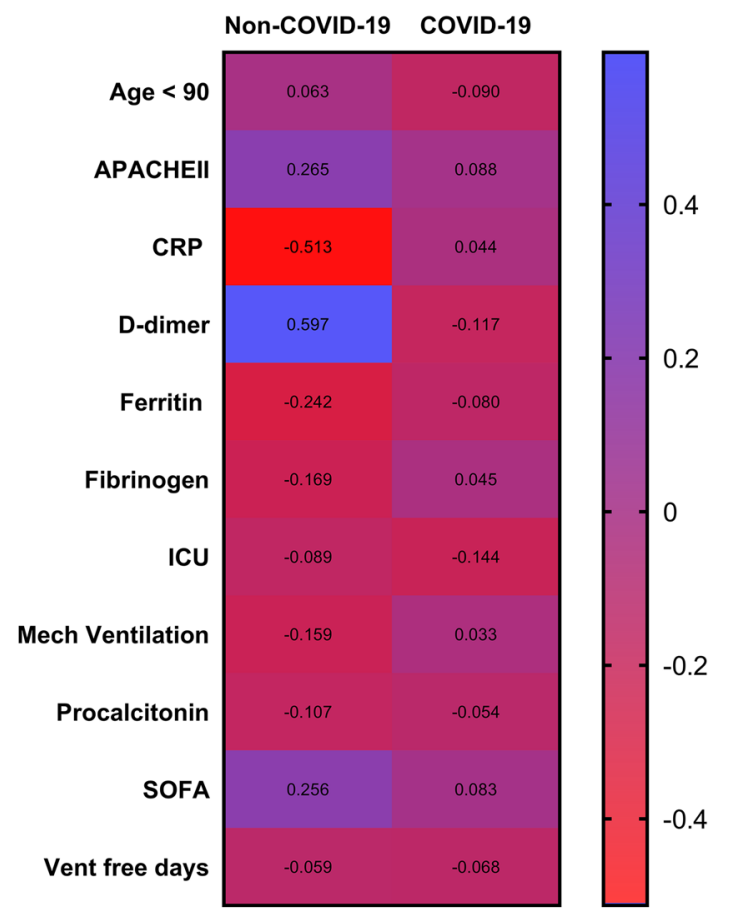

Fig. 3 Relative expression of tissue factor ( $F 3$ gene) in the population of total leukocytes in the two groups of non-COVID-19 and COVID-19 patients (A) and its correlation with available clinical,

damage-associated molecular patterns (DAMPs) include $\mathrm{ATP}, \mathrm{NAD}^{+}$, and $\mathrm{K}^{+}$, which have a high inflammatory potential and are important players in purinergic signaling (Fig. 4).

\section{Correlations between nucleotide and nucleoside levels and clinical features}

The high inflammatory state of COVID-19 promotes platelet activation and thromboinflammation [26, 59-63]. In
C

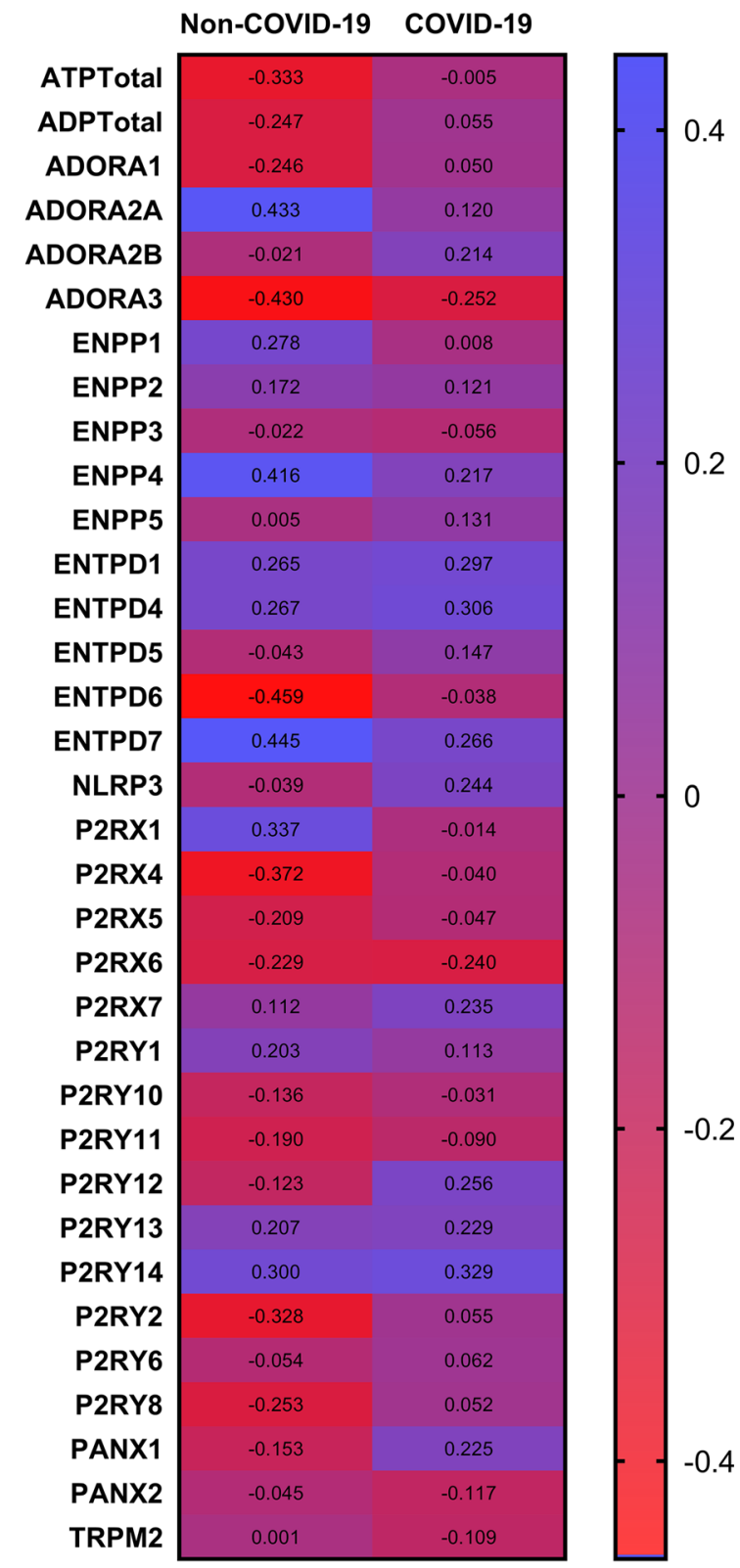

metabolomics $(\mathbf{B})$, and transcriptomics features $(\mathbf{C})$. The intensity of the colors is proportional to the positive (blue) and negative (red) correlation coefficient

this study, we focused on the analysis of the nucleotides/ nucleosides ATP, ADP, AMP, adenosine, inosine, hypoxanthine, and xanthine present in the peripheral blood. We also focused on their correlations with other elements of blood coagulation, such as fibrinogen, fibrinopeptides, and coagulation cascade components. These correlations may lead to helpful biomarkers for predicting disease severity, improving the clinical management of infected patients and providing more information about the pathogenesis of hypercoagulability present in COVID-19 patients. 


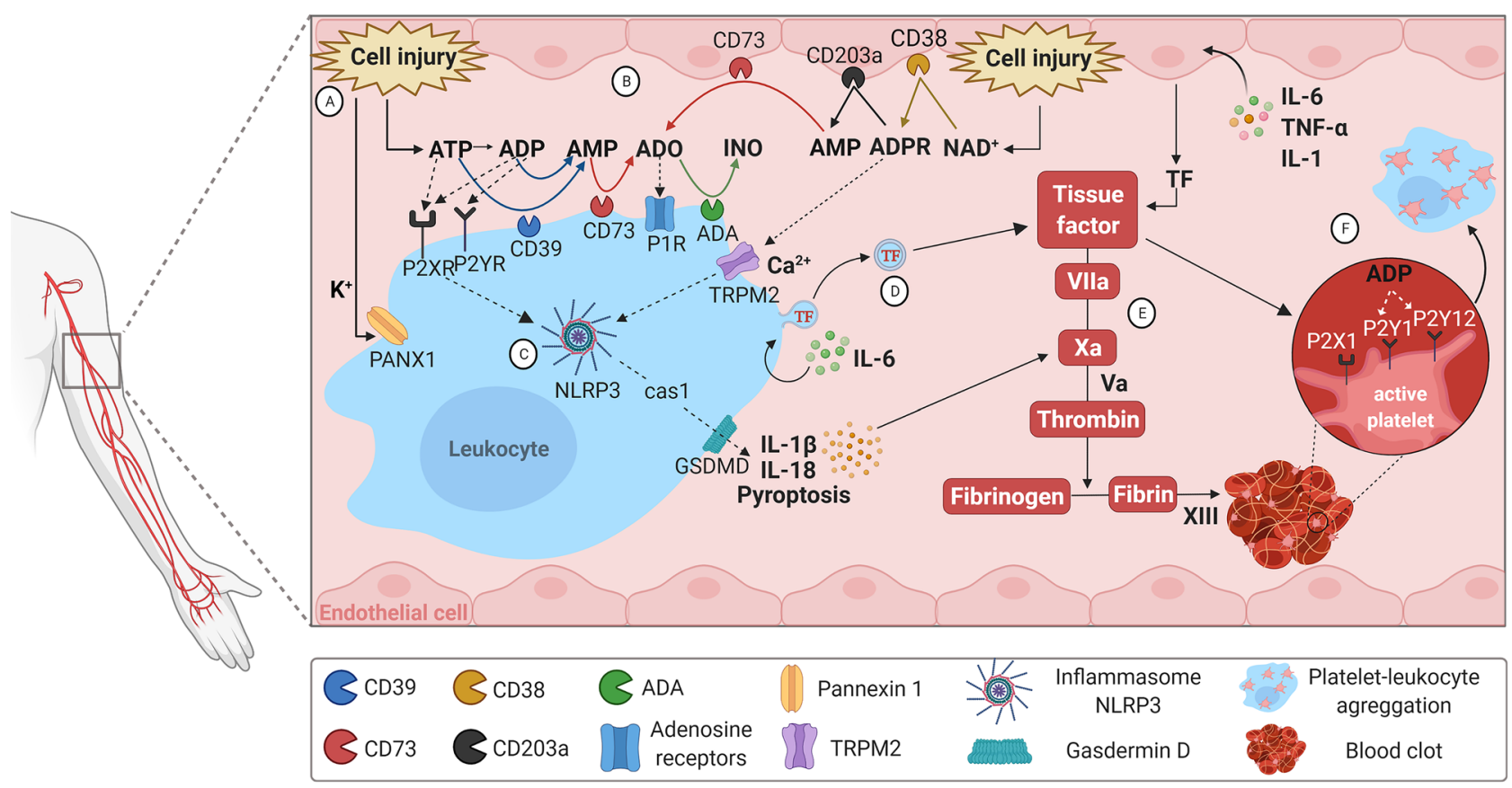

Fig. 4 a Direct viral infection of the host cell by Sars-CoV-2 or cell injury caused by thrombosis and inflammation release damage molecular patterns (DAMPs) and pathogen-associated molecular patterns (PAMPs) to the extracellular microenvironment. b Among the DAMPs released, the adenosine triphosphate (ATP) and nicotinamide adenine dinucleotide $\left(\mathrm{NAD}^{+}\right)$play a pivotal role as signaling molecules in the purinergic system. c The activation of the P2X7 receptor by ATP is the main way of activation of the NLRP3 inflammasome. Other pathways may also perform this activity, such as ADP-

We showed negative correlations between inosine and platelet, WBC, and monocyte counts in the non-severe COVID-19 group. The patients from this group usually recover from the disease, and, for that, these negative correlations could be explained by the immunothrombosis [25]. Also, the increased levels of inosine could be caused by the body's attempt to resolve the immunothrombosis, acting on immune cells and fighting against the excessive inflammation. These actions of inosine have been previously reported, but the mechanism of action remains unclear [64-66]. Recently, Xiao et al. showed, through an integrated study of metabolomics (targeted and untargeted) and cytokine/chemokine profiling, the relationship between the cytokines and metabolites present in samples from COVID19 patients. Their analysis demonstrated a reprogramming of immunometabolism where, after targeting elements of pathways including purine metabolism, pro-inflammatory cytokine release is altered in PBMCs. They also showed that purine levels increase gradually over time and then decrease in the late phases of the disease in follow-up of hospitalized patients with mild disease (4-36 days after symptom onset). Moreover, when the different groups were analyzed, there was an increase in adenosine, hypoxanthine, and xanthine in ribose and the increase of intracellular $\mathrm{Ca}^{2+}$ levels due to the TRPM2 channel, activated by ADPR. The NLRP3 inflammasome activates caspase 1 that cleaves pro-IL1 $\beta$ and IL-18, releasing these cytokines resulting in pyroptosis cell death. $\mathbf{d}$ The tissue factor (F3) gene upregulation by the immune cells is directly linked to circulating levels of extracellular vesicles containing TF (EV-TF). e This high circulating TF stimulates the platelets, leading to the formation of blood clots. $\mathbf{f}$ Also, high levels and upregulation of TF promote platelet-leukocytes aggregation causing the immunothrombosis

the severe group of patients compared to healthy volunteers [58].

A review published by Sliva et al. discussed the antiviral and immunomodulatory actions of isoprinosine (inosine pranobex; IPNX) against multiple diseases and infections. Various effects of IPNX have been suggested, such as the blockage of viral RNA transcription, production of cytokines, differentiation and expansion of T cells, and modulation of NK cells, enhancing their activity [64]. Therefore, inosine has been evaluated in clinical trials as an alternative to prevent or treat COVID-19. At the time of submission of this paper, there are three registered phase III clinical trials, two using isoprinosine (NCT04383717 and NCT04360122) as prophylaxis and one using Molixan (NCT04780672) as a treatment measure. Yet, the preliminary clinical use of inosine pranobex significantly decreases the mortality and infection rates caused by SARS-CoV-2 in elderly patients from three different locations in the Czech Republic [67].

In the COVID-19 group, our results showed positive correlations of ATP and AMP with CRP, a clinical marker for inflammation in peripheral blood with pleiotropic function. Considering that the production of CRP occurs mainly in the liver in response to elevated circulating levels of IL- $1 \beta$ 
and IL-6 [68], we suggest that ATP and AMP may trigger the release of IL-1 $\beta$, resulting in $\mathrm{P} 2$ receptor and inflammasome NLRP3 activation, in a similar mechanism to that demonstrated by Bian et al. [69].

Regarding ATP, ADP, AMP and hypoxanthine, our results suggest that these molecules can activate blood coagulation, considering their positive correlations with the protein necessary for clot formation, fibrinogen, and the protein originating from blood clot lysis, the D-dimer. Yet, severe COVID-19 patients show critical hypoxemia, possibly due to vessel occlusion by these clots. The levels of hypoxemia could be measured using the circulating amounts of plasma hypoxanthine as a point-of-care measurement, as mentioned in the literature [70]. Levels of hypoxanthine and its oxidized metabolite xanthine are indeed present in higher concentrations in COVID-19 patients' peripheral blood circulation, as recently shown by other metabolomics studies. Danlos et al. and Páez-Franco et al. reported statistical analysis that confirms alterations in purine metabolism [71, 72]. Another purine metabolite that could be used as a biomarker to investigate ischemic events, due to its long blood half-life, is the precursor of hypoxanthine, inosine (see below).

\section{Purinergic profile of circulating immune cells}

In physiological conditions, the crosstalk between circulating metabolites and cells is essential for the maintenance of metabolism. In COVID-19, due to multiple factors, the cells are damaged and release DAMPs and PAMPs into the extracellular microenvironment. These components are recognized by immune cells, which initiate signaling pathways that aim to clear the infection. In our three analyzed datasets from the GEO database, we have different immune cell populations: total leukocytes, buffy coat population (WBC+ platelets), and CD14+monocytes. For the latter, the literature reports that BALF and peripheral blood single-cell RNA sequencing analysis from severe COVID-19 patients presented an expansion of the CD14+ monocyte population when compared to mild cases or healthy controls [73-75]. Moreover, Wilk et al. created the cellxgene application, confirming that there is an increase in CD14+ monocytes, with high inflammatory gene expression [76]. Therefore, we can conclude that our three analyzed leukocyte populations are mostly comprised of CD14+ monocytes.

In Fig. 4, we schematically show platelet activation and leukocyte-platelet aggregation by autocrine and paracrine biomolecules, such as ADP, through the specific receptors P2Y1 and P2Y12 [25, 77]. In addition, it highlights the upregulation of monocyte tissue factor as an important event in starting the coagulation cascade [78]. In accordance, our analysis showed the upregulation of TF in the COVID-19 group. Consequently, this upregulation promotes an elevation of extracellular vesicles with circulating TF (EV-TF), the levels of which positively correlate with clinical features, including leukocyte levels and COVID-19 stages [79]. High levels of these EV-TFs also show positive correlations with other coagulation proteins such as fibrinogen, D-dimer, and Von Willebrand factor [80]. Moreover, our analyzed datasets showed an upregulation of $P 2 R Y 1$ and $P 2 R Y 12$ on leukocytes, and the heatmap showed their correlation with TF levels (Fig. 3C). Therefore, the inhibition of the interaction between ADP and the P2Y receptors, as suggested by recent studies [26, 63], could indeed decrease TF expression, EV-TF circulation, and levels of platelet-leukocyte and platelet-platelet conjugates, consequently reducing the risk of immunothrombosis development in COVID-19.

Extracellular ATP and NAD ${ }^{+}$levels can be enhanced by the pannexin 1 channel, encoded by the PANX1 gene [81] This channel is located on the plasma membrane surface, allowing the leakage of small biomolecules such as ATP, $\mathrm{NAD}^{+}, \mathrm{PGE}_{2}$ and glutamate upon physiological stimuli, as increase in intracellular calcium $\left(\mathrm{Ca}^{2+}{ }_{\mathrm{i}}\right)$ [82] extracellular $\mathrm{K}^{+}$[43], activation by TNF- $\alpha$ [83]; or mechanical stimuli, as plasma membrane stretch. The ATP released into the extracellular microenvironment acts as a "danger signal" and promotes migration of leukocytes, especially phagocytes, to control the inflammation and clear cell and pathogen debris [83, 84]. For example, macrophages release ATP by exocytosis and through pannexin channels in response to viral infections [85]. Thus, the prospect of targeting this channel as a therapy for fighting COVID-19 was recently raised and discussed by Swayne et al. [86]. In accordance, our results showed higher expression of the pannexin 1 channel in COVID-19 patients. Therefore, this approach could be a good avenue to be investigated, in an attempt to avoid excessive leakage of ATP and subsequent immune cell infiltration into the lungs, the primary site of infection.

Among the P2X subfamily, the P2X7 receptor (encoded by the $P 2 R X 7$ gene) is one of the most studied receptors in inflammation and immunity [87]. It is specialized in detecting high levels of eATP $[88,89]$. The P2X7 receptor is significantly expressed in alveolar cell type I [90]; therefore, these cells are able to receive the ATP released by the alveolar cell type II, the main cell type infected by SARS-CoV-2, and become activated. The activation of the $\mathrm{P} 2 \mathrm{X} 7$ receptor may have ambiguous functions; it can decrease viral replication and infection, but, if uncontrolled, it also can boost inflammation and may potentially contribute to an exacerbated immune response, depending on the virulence of the pathogen and severity of the infection [91]. To date, the P2X7 receptor has been shown to be a strong activator of the NLRP3 inflammasome and therefore of caspase-1 cleavage and release of mature IL-1 $\beta$ and IL-18 [87]. In addition, the notable involvement of the inflammasome in COVID-19 has been recently discussed in multiple reports [24, 87, 92-96]. 
Yet, the P2X7 receptor has been suggested to be associated with inflammation and coagulation, since its stimulation of macrophage and dendritic cells upregulates the expression and release of microvesicles containing tissue factor, thus producing a pro-thrombotic response, as discussed above [97, 98]. Genetic depletion or pharmacologic blockade of the P2X7 receptor improved the outcome of animals with acute respiratory distress syndrome. One explanation for this could be a reduction in inflammatory markers such as IL-6 and IL- $1 \beta$, as well as the reduction of neutrophil infiltration into the lungs.

Recently, Klaver and Thurnher reviewed the influence of P2Y receptors on inflammatory processes of monocytes and macrophages in physiological settings and infectious diseases including COVID-19 [99]. Although we did not see any significant modulation of P2YR14, another study has suggested that by targeting this receptor, neutrophilia and NETosis formation, an important event in immunothrombosis, could be attenuated, minimizing thrombotic complications of COVID-19 [100].

As our results showed higher expression of $C D 38$ and its positive correlation with $P 2 R X 7$ in COVID-19 samples, we suggest that ADPR may participate in the activation of this purine receptor. ADPR is a biomolecule that comes from the metabolization of $\mathrm{NAD}^{+}$by $C D 38$ and can activate the $\mathrm{P} 2 \mathrm{X} 7$ receptor, although in a weaker manner than ATP $[43,101]$. The TRPM2 is a $\mathrm{Ca}^{2+}$ permeable, non-selective cation channel, which is activated by ADPR, temperature, oxidative stress, and $\mathrm{Ca}^{2+}$ levels [102], and works as a controller of chemotaxis of neutrophils, macrophages, and DCs to infection sites [103, 104]. In a recent review, Wang et al. discussed the role of TRPM2 in NLRP3 inflammasome activation and demonstrated an interplay of $\mathrm{Ca}^{2+}$ influx, reactive oxygen species production, and, consequently, the activation of the NLRP3 inflammasome [105]. Thus, as the TRPM2 is downregulated, the activation of the inflammasome NLRP3 may not be through this axis and reinforce that the major activation of NLRP3 is via P2X7 activation, although further studies are still necessary.

As discussed above, COVID-19 patients have high levels of inosine in the peripheral blood circulation in a disease severity-dependent manner. One reason for this could be the longer half-life of this biomolecule compared to other nucleotides and nucleosides. The blood half-life of inosine is around $15 \mathrm{~h}$, compared to the blood half-life of adenosine of around $10 \mathrm{~s}$ [106]. Considering the upregulation of two ectoenzymes involved in the adenosinergic pathway (ENTPD1 and $C D 38$ ) and the low half-life time of adenosine, we may surmise that the levels of adenosine are higher than those quantified by the studies we analyzed. Furthermore, in our analysis, we show the following: (1) a strong correlation between $C D 38$ and PANXI levels $(r=0.730 ; p<0.0001)$;
(2) a weak correlation between ENTPDI and PANX1 levels ( $r=0.302 ; p=0.002)$; and (3) upregulation of $A D A$ and its correlation with $C D 38$, but not with $E N T P D 1$. Thus, taken altogether, it is possible to suggest that $\mathrm{NAD}^{+}$is released by the pannexin 1 channel at higher levels than ATP. These higher amounts of $\mathrm{NAD}^{+}$are metabolized by $C D 38$, following the non-canonical adenosinergic axis, until originate adenosine and sequentially inosine by upregulated $A D A$ (Fig. 1).

Additionally, as mentioned before, inosine is present at high circulating levels, associated with its long half-life and the upregulation of the PNP enzyme that is responsible for the degradation of inosine into hypoxanthine. Inosine also participates in the nucleotide salvage pathway, leading us to hypothesize that the excessive levels of inosine act to boost the generation of ATP and ADP in the immune cells, releasing these nucleotides into the extracellular space and causing a signaling loop and chemotaxis of more immune cells to the inflammation site, and initiating platelet aggregation through the stimulation of specific receptors.

Reports are suggesting that targeting the adenosine pathway could help to treat COVID-19 [93, 107]. Abouelkhair raised the hypothesis that the modulation of $\mathrm{CD} 39, \mathrm{CD} 73$, and A2AR could be a good therapeutic option for treating COVID-19. The author suggested the use of anti-CD39 and anti-CD73 monoclonal antibodies to avoid eATP hydrolysis by the ectoenzymes, maintaining the nucleotide at high levels in the microenvironment, and consequently maintaining IFN-I production, resulting in an "antiviral state." Another suggestion was the inhibition of A2AR (ADORA2A) using a receptor antagonist to avoid the immunosuppressive effect of adenosine in the immune cells [108]. However, as we show, the non-canonical adenosinergic pathway is also activated. Therefore, the approach proposed could help, but it is not the only or best alternative, as the analysis did not show an upregulation of A2AR and CD73, but only of CD39 (ENTPDI) expression.

Lastly, Arunachalam et al. analyzed blood samples from COVID-19 patients from two different cohorts and compared them to healthy controls. The authors split the total leukocyte population into clusters according to specific features and analyzed the differentially expressed genes in each cluster, compared with all other cells. Multiple cell clusters from COVID-19 patients, when compared to the same cell cluster from healthy individuals, showed an upregulation of CD38, ENTPD1, GSDMD, P2RX5, NT5C, NT5C2, and $N T 5 C 3 A$. However, P2RY13, NLRP3, and NT5C were found to be downregulated in three different clusters of monocytes and one cluster of T cells [109]. These findings corroborate some of our own, for example, the upregulation of $C D 38$ and ENTPDI in the total leukocyte population.

Although these findings open new avenues for understanding the mechanisms underlying the role of purinergic 
signaling in the main physiological disturbances associated with the severity of COVID-19, many questions are still open. Therefore, the main limitations of our study are: (1) The datasets used have complementary information, so each dataset does not have all the data needed to assess all correlations; (2) as the blood samples were collected by the authors from other studies and we used the publiclyavailable raw data, we could not control which medications the patients were taking at the time of sample collection, which may act as a bias in our correlation analysis; (3) none of the analyzed public datasets have the quantification of $\mathrm{NAD}^{+}$and ADPR, which makes it impossible to correlate these parameters with the clinical data or the other nucleotides and nucleosides. In addition, we must consider the low stability of ATP, AMP, ADP, and adenosine, which means that the pre-analytical handling of the samples could interfere in the metabolite quantification, for example due to hemolysis causing the release of intracellular nucleotides; and (4) despite our analysis being fully based on patient data, it was based on a general population of leukocytes, with only one dataset showing data from a specific cell type (CD14+ monocytes). Thus, further studies are still required to fully understand the mechanism of action of each biomolecule, their interplay, and the signaling pathways involved with each specific cell type.

In conclusion, in this study, we explored the nucleotides and nucleosides, purinoreceptors, and ectoenzymes of the canonical and noncanonical adenosinergic pathway in the blood and immune cells of COVID-19 patients. The main finding of our study is that inosine levels are increased in COVID-19, in a severity-dependent manner. Inosine levels are associated with the levels of the pannexin 1 channel, ATP, $\mathrm{NAD}^{+}$, and the ectoenzymes CD38, CD39, and ADA. As discussed, ATP, ADP AMP, inosine, hypoxanthine, purinoreceptors, and ectoenzymes play roles in the disturbances of inflammation and coagulation present in COVID-19. Therefore, approaches targeting these biomolecules or their specific purinoreceptors and ectoenzymes may attenuate the high inflammatory state and coagulopathy seen in COVID19 patients.

Supplementary information The online version contains supplementary material available at https://doi.org/10.1007/s00109-021-02175-y.

Author contribution ICS and APSB performed the data analysis and manuscript writing. MRW reviewed the manuscript.

Funding ICS is a recipient of a $\mathrm{PhD}$ scholarship from Coordenação de Aperfeiçoamento de Pessoal de Nível Superior - Brazil (CAPES). APSB is a recipient of a postdoc fellowship from Coordenação de Aperfeiçoamento de Pessoal de Nível Superior - Brazil (CAPES)/ Programa Nacional de Pós-Doutorado (PNPD). MRW is a recipient of productivity research fellowship from $\mathrm{CNPq}$ (Conselho Nacional de Desenvolvimento Científico e Tecnológico). This study was supported by CNPq MS-SCTIE-Decit/CNPq nº 12/2018 (441575/2018-8),
MS-SCTIE-DECIT-DGITIS-CGCIS/CNPq n ${ }^{\circ}$ 26/2020 (442586/2020 5), and CAPES (COMBATE-COVID 1694577P).

Availability of data and material All data are available in the main text or the supplementary materials.

Code availability Not applicable.

\section{Declarations}

Ethics approval Not applicable.

Consent to participate Not applicable.

Consent for publication Not applicable.

Conflict of interest The authors declare no competing interests.

\section{References}

1. Zhu N, Zhang D, Wang W, Li X, Yang B, Song J et al (2020) A novel coronavirus from patients with pneumonia in China 2019. N Engl J Med 382(8):727-733

2. Lu R, Zhao X, Li J, Niu P, Yang B, Wu H et al (2020) Genomic characterisation and epidemiology of 2019 novel coronavirus: implications for virus origins and receptor binding. Lancet 395(10224):565-574. https://doi.org/10.1016/S0140-6736(20) 30251-8

3. Tang JW, Toovey OTR, Harvey KN, Hui DDS (2021) Introduction of the South African SARS-CoV-2 variant 501Y.V2 into the UK. J Infect 82(4):e8-e10. https://linkinghub.elsevier.com/retrieve/pii/ S016344532100030X

4. Martins AF, Zavascki AP, Wink PL, Volpato FCZ, Monteiro FL, Rosset C et al (2021) Detection of SARS-CoV-2 lineage P.1 in patients from a region with exponentially increasing hospitalisation rate February 2021 Rio Grande do Sul Southern Brazil. Eurosurveil 26(12):2100276

5. Daniloski Z, Guo X, Sanjana NE (2020) The Spike D614G mutation increases SARS-CoV-2 infection of multiple human cell types. bioRxiv Prepr Serv Biol 1-16

6. Ackermann M, Verleden SE, Kuehnel M, Haverich A, Welte $\mathrm{T}$, Laenger $\mathrm{F}$ et al (2020) Pulmonary vascular endothelialitis, thrombosis, and angiogenesis in Covid-19. N Engl J Med 383:120-128

7. Benedetti C, Waldman M, Zaza G, Riella LV, Cravedi P (2020) COVID-19 and the kidneys: an update. Front Med 7:423

8. Guo T, Fan Y, Chen M, Wu X, Zhang L, He T et al (2020) Cardiovascular implications of fatal outcomes of patients with coronavirus disease 2019 (COVID-19). JAMA Cardiol 5(7):811-818

9. Zou X, Chen K, Zou J, Han P, Hao J, Han Z (2020) Single-cell RNA-seq data analysis on the receptor ACE2 expression reveals the potential risk of different human organs vulnerable to 2019nCoV infection. Front Med 14(2):185-192

10. Wiersinga WJ, Rhodes A, Cheng AC, Peacock SJ, Prescott HC (2020) Pathophysiology, transmission, diagnosis, and treatment of coronavirus disease 2019 (COVID-19): a review. JAMA J Am Med Assoc 324(8):782-793

11. Hoffmann M, Kleine-Weber H, Schroeder S, Krüger N, Herrler T, Erichsen S et al (2020) SARS-CoV-2 cell entry depends on ACE2 and TMPRSS 2 and is blocked by a clinically proven protease inhibitor. Cell 181(2):271-280 
12. Gandhi RT, Lynch JB, del Rio C (2020) Mild or moderate Covid19. N Engl J Med 383(18):1757-1766

13. Berlin DA, Gulick RM, Martinez FJ (2020) Severe Covid-19. N Engl J Med 383(25):2451-2460

14. Song JW, Zhang C, Fan X, Meng FP, Xu Z, Xia P et al (2020) Immunological and inflammatory profiles in mild and severe cases of COVID-19. Nat Commun 11(1):3410

15. Zhou F, Yu T, Du R, Fan G, Liu Y, Liu Z et al (2020) Clinical course and risk factors for mortality of adult inpatients with COVID-19 in Wuhan, China: a retrospective cohort study. Lancet 395(10229):1054-1062. https://doi.org/10.1016/S0140-6736(20) 30566-3

16. Tang N, Li D, Wang X, Sun Z (2020) Abnormal coagulation parameters are associated with poor prognosis in patients with novel coronavirus pneumonia. J Thromb Haemost 18(4):844-847

17. Long X, Zhang Z, Zou W, Ling J, Li D, Jing L et al (2020) Coagulopathy of patients with covid-19 is associated with infectious and inflammatory markers. Risk Manag Healthc Policy 13:1965-1975

18. Tang N, Bai H, Chen X, Gong J, Li D, Sun Z (2020) Anticoagulant treatment is associated with decreased mortality in severe coronavirus disease 2019 patients with coagulopathy. J Thromb Haemost 18(5):1094-1099

19. Tay MZ, Poh CM, Rénia L, MacAry PA, Ng LFP (2020) The trinity of COVID-19: immunity, inflammation and intervention. Nat Rev Immunol 20(6):363-374

20. Huang C, Wang Y, Li X, Ren L, Zhao J, Hu Y et al (2020) Clinical features of patients infected with 2019 novel coronavirus in Wuhan China. Lancet 395(10223):497-506

21. Liu Y, Yang Y, Zhang C, Huang F, Wang F, Yuan J et al (2020) Clinical and biochemical indexes from 2019-nCoV infected patients linked. Sci China Life Sci 63(3):364-374

22. Can A, Coskun H (2020) The rationale of using mesenchymal stem cells in patients with COVID-19-related acute respiratory distress syndrome: What to expect. Stem Cells Transl Med 9(11):1287-1302

23. Rogers CJ, Harman RJ, Bunnell BA, Schreiber MA, Xiang C, Wang FS et al (2020) Rationale for the clinical use of adiposederived mesenchymal stem cells for COVID-19 patients. J Transl Med 18(1):1-19. https://doi.org/10.1186/s12967-020-02380-2

24. Rodrigues TS, S KSG De, Santana RC, Vilar FC, Auxiliadoramartins M, Luppino-assad R et al (2020) Inflammasomes are activated in response to SARS-CoV-2 infection and are associated with COVID-19 severity in patients. J Exp Med 218(3)

25. Engelmann B, Massberg S (2013) Thrombosis as an intravascular effector of innate immunity. Nat Rev Immunol 13(1):34-45. https://doi.org/10.1038/nri3345

26. Gu SX, Tyagi T, Jain K, Gu VW, Lee SH, Hwa JM et al (2020) Thrombocytopathy and endotheliopathy: crucial contributors to COVID-19 thromboinflammation. Nat Rev Cardiol 18:194209. https://doi.org/10.1038/s41569-020-00469-1

27. Klok FA, Kruip MJHA, van der Meer NJM, Arbous MS, Gommers DAMPJ, Kant KM et al (2020) Incidence of thrombotic complications in critically ill ICU patients with COVID-19. Thromb Res 191:145-147. https://doi.org/10. 1016/j.thromres.2020.04.013

28. Diorio C, McNerney KO, Lambert M, Paessler M, Anderson EM, Henrickson SE et al (2020) Evidence of thrombotic microangiopathy in children with SARS-CoV-2 across the spectrum of clinical presentations. Blood Adv 4(23):6051-6063

29. Spyropoulos AC, Levy JH, Ageno W, Connors JM, Hunt BJ, Iba T et al (2020) Scientific and Standardization Committee communication: Clinical guidance on the diagnosis, prevention, and treatment of venous thromboembolism in hospitalized patients with COVID-19. J Thromb Haemost 18(8):1859-1865
30. Thachil J, Tang N, Gando S, Falanga A, Cattaneo M, Levi M et al (2020) ISTH interim guidance on recognition and management of coagulopathy in COVID-19. J Thromb Haemost 18(5):1023-1026

31. WHO Solidarity Trial Consortium (2021) Repurposed antiviral drugs for Covid-19 - Interim WHO solidarity trial results. N Engl J Med 384(6):497-511. https://doi.org/10. 1056/NEJMoa2023184

32. Wahl A, Gralinski LE, Johnson CE, Yao W, Kovarova M, Dinnon KH et al (2021) SARS-CoV-2 infection is effectively treated and prevented by EIDD-2801. Nature 591(7850):451457. http://www.ncbi.nlm.nih.gov/pubmed/33561864

33. Schultz IC, Bertoni APS, Wink MR (2021) Mesenchymal stem cell-derived extracellular vesicles carrying miRNA as a potential multi target therapy to COVID-19: an in silico analysis. Stem Cell Rev Reports 17(2):341-356. https://doi.org/10.1007/ s12015-021-10122-0

34. Li H, Zhou Y, Zhang M, Wang H, Zhao Q (2020) Updated approaches against SARS-CoV-2. Antimicrob Agents Chemother 64(6): 1-7

35. McFee RB (2020) COVID-19: Therapeutics and interventions currently under consideration. Disease-a-Month 66(9):101058

36. Chen S-J, Wang S-C, Chen Y-C (2020) Novel antiviral strategies in the treatment of COVID-19: a review. Microorganisms 8(9):1259. http://www.ncbi.nlm.nih.gov/pubmed/32825283

37. Hossein-khannazer N, Shokoohian B, Shpichka A, Aghdaei HA, Timashev P, Vosough M (2021) An update to "novel therapeutic approaches for treatment of COVID-19." J Mol Med 99(2):303-310

38. Cao X (2020) COVID-19: immunopathology and its implications for therapy. Nat Rev Immunol 20(5):269-270. https://doi. org/10.1038/s41577-020-0308-3

39. Bolourani S, Brenner M, Wang P (2021) The interplay of DAMPs, TLR4, and proinflammatory cytokines in pulmonary fibrosis. J Mol Med 99(10):1373-1384. https://doi.org/10. 1007/s00109-021-02113-y

40. Riteau N, Gasse P, Fauconnier L, Gombault A, Couegnat M, Fick L et al (2010) Extracellular ATP is a danger signal activating P2X7 receptor in lung inflammation and fibrosis. Am J Respir Crit Care Med 182(6):774-783

41. Penuela S, Gehi R (1828) Laird DW (2013) The biochemistry and function of pannexin channels. Biochim Biophys Acta Biomembr 1:15-22. https://doi.org/10.1016/j.bbamem.2012. 01.017

42. Wang N, De Bock M, Decrock E, Bol M, Gadicherla A, Vinken $M$ et al (1828) (2013) Paracrine signaling through plasma membrane hemichannels. Biochim Biophys Acta Biomembr $1: 35-50$

43. Linden J, Koch-Nolte F, Dahl G (2019) Purine release, metabolism, and signaling in the inflammatory response. Annu Rev Immunol 37:325-347

44. Burnstock G (2007) Physiology and pathophysiology of purinergic neurotransmission. Physiol Rev 87(2):659-797

45. Ferretti E, Horenstein AL, Canzonetta C, Costa F, Morandi F (2019) Canonical and non-canonical adenosinergic pathways. Immunol Lett 205:25-30. https://doi.org/10.1016/j.imlet.2018. 03.007

46. Cekic C, Linden J (2016) Purinergic regulation of the immune system. Nat Rev Immunol 16(3):177-192

47. DiNicolantonio JJ, Barroso-Aranda J (2020) Harnessing adenosine A2A receptors as a strategy for suppressing the lung inflammation and thrombotic complications of COVID-19: Potential of pentoxifylline and dipyridamole. Med Hypotheses 143:110051. https://linkinghub.elsevier.com/retrieve/pii/ S0306987720317382 
48. Di Giorgio S, Martignano F, Torcia MG, Mattiuz G, Conticello SG (2020) Evidence for host-dependent RNA editing in the transcriptome of SARS-CoV-2. Sci Adv 6(25):1-9

49. Doğan HO, Şenol O, Bolat S, Yıldız ŞN, Büyüktuna SA, Sariismailoğlu R et al (2021) Understanding the pathophysiological changes via untargeted metabolomics in COVID-19 patients. J Med Virol 93(4):2340-2349. https://doi.org/10.1002/jmv.26716

50. Overmyer KA, Shishkova E, Miller IJ, Balnis J, Bernstein MN, Peters-Clarke TM et al (2020) Large-scale multi-omic analysis of COVID-19 severity. Cell Syst 12(1):23-40. https://doi.org/10. 1016/j.cels.2020.10.003

51. Shen B, Yi X, Sun Y, Bi X, Du J, Zhang C et al (2020) Proteomic and metabolomic characterization of COVID-19 patient sera. Cell 182(1):59-72

52. Gill SE, dos Santos CC, O'Gorman DB, Carter DE, Patterson EK, Slessarev M et al (2020) Transcriptional profiling of leukocytes in critically ill COVID19 patients: implications for interferon response and coagulation. Intensive Care Med Exp 8(1):75. https://doi.org/10.1186/s40635-020-00361-9

53. Brunetta E, Folci M, Bottazzi B, De Santis M, Gritti G, Protti A et al (2021) Macrophage expression and prognostic significance of the long pentraxin PTX3 in COVID-19. Nat Immunol 22(1):19-24. https://doi.org/10.1038/s41590-020-00832-x

54. Young JD (2016) The SLC28 (CNT) and SLC29 (ENT) nucleoside transporter families: A 30-year collaborative odyssey. Biochem Soc Trans 44(3):869-876

55. Horenstein AL, Chillemi A, Zaccarello G, Bruzzone S, Quarona V, Zito A et al (2013) A CD38/CD203A/CD73 ectoenzymatic pathway independent of CD39 drives a novel adenosinergic loop in human T lymphocytes. Oncoimmunology 2(9):37-41

56. Allard B, Allard D, Buisseret L, Stagg J (2020) The adenosine pathway in immuno-oncology. Nat Rev Clin Oncol 17(10):611-629

57. de Almeida Chuffa LG, Freire PP, dos Santos SJ, de Mello MC, de Oliveira NM, Carvalho RF (2021) Aging whole blood transcriptome reveals candidate genes for SARS-CoV-2-related vascular and immune alterations. J Mol Med. https://doi.org/10. 1007/s00109-021-02161-4

58. Xiao N, Nie M, Pang H, Wang B, Hu J, Meng X et al (2021) Integrated cytokine and metabolite analysis reveals immunometabolic reprogramming in COVID-19 patients with therapeutic implications. Nat Commun 12(1):1-13

59. McGonagle D, O’Donnell JS, Sharif K, Emery P, Bridgewood C (2020) Immune mechanisms of pulmonary intravascular coagulopathy in COVID-19 pneumonia. Lancet Rheumatol 2(7):e437e445. https://doi.org/10.1016/S2665-9913(20)30121-1

60. Jose RJ, Manuel A (2020) COVID-19 cytokine storm: the interplay between inflammation and coagulation. Lancet Respir Med 8(6):e46-e47. https://doi.org/10.1016/S2213-2600(20)30216-2

61. Mehta P, Haskard DO, Laffan MA, Chambers RC, Hunt BJ (2021) Thromboses and COVID-19: reducing inflammation in addition to thromboprophylaxis. Lancet Rheumatol 3(3):e171e172. https://doi.org/10.1016/S2665-9913(21)00003-5

62. Levi M, Thachil J, Iba T, Levy JH (2020) Coagulation abnormalities and thrombosis in patients with COVID-19. Lancet Haematol 7(6): $4338-\mathrm{e} 440$

63. Sriram K, Insel PA (2021) Inflammation and thrombosis in COVID-19 pathophysiology: proteinase-activated and purinergic receptors as drivers and candidate therapeutic targets. Physiol Rev 101(2):545-567. https://doi.org/10.1152/physrev.00035.2020

64. Sliva J, Pantzartzi CN, Votava M (2019) Inosine Pranobex: a key player in the game against a wide range of viral infections and non-infectious diseases. Adv Ther 36(8):1878-1905. https://doi. org/10.1007/s12325-019-00995-6

65. Fuentes E, Pereira J, Mezzano D, Alarcón M, Caballero J, Palomo I (2014) Inhibition of platelet activation and thrombus formation by adenosine and inosine: studies on their relative contribution and molecular modeling. PLoS ONE 9(11):1-9

66. Marton A, Pacher P, Murthy KG, Németh ZH, Haskó G, Szabó C (2001) Anti-inflammatory effects of inosine in human monocytes, neutrophils and epithelial cells in vitro. Int J Mol Med 8(6):617-621

67. Beran J, Špajdel M, Katzerová V, Holoušová A, Malyš J, Rousková JF et al (2020) Inosine pranobex significantly decreased the case-fatality rate among PCR positive elderly with SARS-CoV-2 at three nursing homes in the Czech Republic. Pathogens 9(12):1-10

68. Richter K, Sagawe S, Hecker A, Küllmar M, Askevold I, Damm $\mathrm{J}$ et al (2018) C-reactive protein stimulates nicotinic acetylcholine receptors to control ATP-mediated monocytic inflammasome activation. Front Immunol 9:1604

69. Bian F, Yang XY, Xu G, Zheng T, Jin S (2019) CRP-Induced NLRP3 inflammasome activation increases LDL transcytosis across endothelial cells. Front Pharmacol 9:1-11

70. Saugstad OD (1988) Hypoxanthine as an indicator of hypoxia: Its role in health and disease through free radical production. Pediatr Res 23(2):143-150

71. Danlos FX, Grajeda-Iglesias C, Durand S, Sauvat A, Roumier M, Cantin D et al (2021) Metabolomic analyses of COVID19 patients unravel stage-dependent and prognostic biomarkers. Cell Death Dis 12(3):1-11. https://doi.org/10.1038/ s41419-021-03540-y

72. Páez-Franco JC, Torres-Ruiz J, Sosa-Hernández VA, CervantesDíaz R, Romero-Ramírez S, Pérez-Fragoso A et al (2021) Metabolomics analysis reveals a modified amino acid metabolism that correlates with altered oxygen homeostasis in COVID-19 patients. Sci Rep 11(1):1-12. https://doi.org/10.1038/s41598-021-85788-0

73. Liao M, Liu Y, Yuan J, Wen Y, Xu G, Zhao J et al (2020) Singlecell landscape of bronchoalveolar immune cells in patients with COVID-19. Nat Med 26(6):842-844. https://doi.org/10.1038/ s41591-020-0901-9

74. Xu G, Qi F, Li H, Yang Q, Wang H, Wang X et al (2020) The differential immune responses to COVID-19 in peripheral and lung revealed by single-cell RNA sequencing. Cell Discov 6(1):1-14. https://doi.org/10.1038/s41421-020-00225-2

75. Wen W, Su W, Tang H, Le W, Zhang X, Zheng Y et al (2020) Immune cell profiling of COVID-19 patients in the recovery stage by single-cell sequencing. Cell Discov 6(1):1-18. https:// doi.org/10.1038/s41421-020-0168-9

76. Wilk AJ, Rustagi A, Zhao NQ, Roque J, Martínez-Colón GJ, McKechnie JL et al (2020) A single-cell atlas of the peripheral immune response in patients with severe COVID-19. Nat Med 26(7):1070-1076

77. Leon C, Alex M, Klocke A, Morgenstern E, Moosbauer C, Eckly A et al (2004) Platelet ADP receptors contribute to the initiation of intravascular coagulation. Blood 103(2):594-600

78. Hottz ED, Azevedo-Quintanilha IG, Palhinha L, Teixeira L, Barreto EA, Pão CRR et al (2020) Platelet activation and platelet-monocyte aggregate formation trigger tissue factor expression in patients with severe COVID-19. Blood 136(11):1330-1341

79. Guervilly C, Bonifay A, Burtey S, Sabatier F, Cauchois R, Abdili E et al (2021) Dissemination of extreme levels of extracellular vesicles: tissue factor activity in patients with severe COVID-19. Blood Adv 5(3):628-634

80. Rosell A, Havervall S, von Meijenfeldt F, Hisada Y, Aguilera K, Grover SP et al (2020) Patients with COVID-19 have elevated levels of circulating extracellular vesicle tissue factor activity that is associated with severity and mortality. Arterioscler Thromb Vasc Biol 41(2):878-882

81. Valdebenito S, Barreto A, Eugenin EA (2018) The role of connexin and pannexin containing channels in the innate and acquired immune response. Biochim Biophys Acta Biomembr 
1860(1):154-165. https://linkinghub.elsevier.com/retrieve/pii/ S0005273617301761

82. Taruno A (2018) ATP release channels. Int J Mol Sci 19(3):808

83. Lohman AW, Leskov IL, Butcher JT, Johnstone SR, Stokes TA, Begandt D et al (2015) Pannexin 1 channels regulate leukocyte emigration through the venous endothelium during acute inflammation. Nat Commun 6:1-12. https://doi.org/10.1038/ncomms8965

84. Adamson SE, Leitinger N (2014) The role of pannexin1 in the induction and resolution of inflammation. FEBS Lett 588(8):1416-1422

85. Zhang C, He H, Wang L, Zhang N, Huang H, Xiong Q et al (2017) Virus-triggered ATP release limits viral replication through facilitating IFN- $\beta$ production in a P2X7-dependent manner. J Immunol 199(4):1372-1381

86. Swayne LA, Johnstone SR, Ng CS, Sanchez-Arias JC, Good ME, Penuela $S$ et al (2020) Consideration of pannexin 1 channels in covid-19 pathology and treatment. Am J Physiol Lung Cell Mol Physiol 319(1):L121-L125

87. Di Virgilio F, Dal Ben D, Sarti AC, Giuliani AL, Falzoni S (2017) The P2X7 receptor in infection and inflammation. Immunity 47(1):15-31. https://doi.org/10.1016/j.immuni.2017.06.020

88. Di Virgilio F, Tang Y, Sarti AC, Rossato M (2020) A rationale for targeting the $\mathrm{P} 2 \mathrm{X} 7$ receptor in Coronavirus disease 19. Br J Pharmacol 177(21):4990-4994

89. Pacheco PAF, Faria RX (2020) The potential involvement of P2X7 receptor in COVID-19 pathogenesis: A new therapeutic target? Scand J Immunol 93(2):e12960

90. Burnstock G, Brouns I, Adriaensen D, Timmermans JP (2012) Purinergic signaling in the airways. Pharmacol Rev 64(4):834-868

91. Savio LEB, de Andrade Mello P, da Silva CG, Coutinho-Silva $\mathrm{R}$ (2018) The P2X7 receptor in inflammatory diseases: angel or demon? Front Pharmacol 9:52

92. Ribeiro DE, Oliveira-Giacomelli Á, Glaser T, Arnaud-Sampaio VF, Andrejew R, Dieckmann L et al (2021) Hyperactivation of P2X7 receptors as a culprit of COVID-19 neuropathology. Mol Psychiatry 26(4):1044-1059. https://doi.org/10.1038/ s41380-020-00965-3

93. Franciosi MLM, Lima MDM, Schetinger MRC, Cardoso AM (2021) Possible role of purinergic signaling in COVID-19. Mol Cell Biochem 476:2891-2898. https://doi.org/10.1007/ s11010-021-04130-4

94. de Rivero Vaccari JC, Dietrich WD, Keane RW, de Rivero Vaccari JP (2020) The Inflammasome in Times of COVID-19. Front Immunol 11:1-15

95. Quagliariello V, Bonelli A, Caronna A, Lombari MC, Conforti G, Libutti M et al (2020) SARS-CoV-2 infection: NLRP3 inflammasome as plausible target to prevent cardiopulmonary complications? Eur Rev Med Pharmacol Sci 24(17):9169-9171

96. van den Berg DF, te Velde AA (2020) Severe COVID-19: NLRP3 inflammasome dysregulated. Front Immunol 11:1-6

97. Moore SF, MacKenzie AB (2007) Murine macrophage P2X7 receptors support rapid prothrombotic responses. Cell Signal 19(4):855-866
98. Baroni M, Pizzirani C, Pinotti M, Ferrari D, Adinolfi E, Calzavarini $S$ et al (2007) Stimulation of P2 (P2X 7) receptors in human dendritic cells induces the release of tissue factor-bearing microparticles. FASEB J 21(8):1926-1933

99. Klaver D, Thurnher M (2021) Control of macrophage inflammation by P2Y purinergic receptors. Cells 10(5):1098

100. Petiz LL et al (2021) P2Y14 receptor as a target for neutrophilia attenuation in severe COVID-19 cases: from hematopoietic stem cell recruitment and chemotaxis to Thrombo-inflammation. Stem Cell Rev Rep 17:241-252

101. Seman M, Adriouch S, Scheuplein F, Krebs C, Freese D, Glowacki $G$ et al (2003) NAD-induced T cell death: ADPribosylation of cell surface proteins by ART2 activates the cytolytic P2X7 purinoceptor. Immunity 19(4):571-582

102. Huang Y, Winkler PA, Sun W, Lü W, Du J (2018) Architecture of the TRPM2 channel and its activation mechanism by ADP-ribose and calcium. Nature 562(7725):145-163

103. Robledo-Avila FH, de Dios Ruiz-Rosado J, Brockman KL, Partida-Sánchez S (2020) The TRPM2 ion channel regulates inflammatory functions of neutrophils during listeria monocytogenes infection. Front Immunol 11:1-18

104. Partida-Sanchez S, Gasser A, Fliegert R, Siebrands CC, Dammermann W, Shi G et al (2007) Chemotaxis of mouse bone marrow neutrophils and dendritic cells is controlled by ADP-ribose, the major product generated by the CD38 enzyme reaction. J Immunol 179(11):7827-7839

105. Wang L, Negro R, Wu H (2020) TRPM2, linking oxidative stress and $\mathrm{Ca} 2+$ permeation to NLRP3 inflammasome activation. Curr Opin Immunol 62:131-135. https://doi.org/10.1016/j.coi.2020. 01.005

106. Welihinda AA, Kaur M, Greene K, Zhai Y, Amento EP (2016) The adenosine metabolite inosine is a functional agonist of the adenosine A2A receptor with a unique signaling bias. Cell Signal 28(6):552-560. https://linkinghub.elsevier.com/retrieve/pii/ S0898656816300353

107. Dos Anjos F, Simões JLB, Assmann CE, Carvalho FB, Bagatini MD (2020) Potential therapeutic role of purinergic receptors in cardiovascular disease mediated by SARS-CoV-2. J Immunol Res 2020:8632048

108. Abouelkhair MA (2020) Targeting adenosinergic pathway and adenosine A2A receptor signaling for the treatment of COVID19: a hypothesis. Med Hypotheses 144:110012. https://linkinghub. elsevier.com/retrieve/pii/S0306987720313384

109. Arunachalam PS, Wimmers F, Mok CKP, Perera RAPM, Scott M, Hagan T et al (2020) Systems biological assessment of immunity to mild versus severe COVID-19 infection in humans. Science 369(6508):1210-1220. https://doi.org/10.1126/science. abc6261

Publisher's Note Springer Nature remains neutral with regard to jurisdictional claims in published maps and institutional affiliations.

Schematic representations were created with Biorender.com. 